\title{
Micropropagação de Zantedeschia spp.: otimização do processo produtivo ${ }^{(1)}$
}

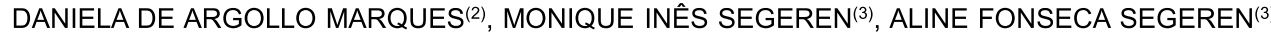 \\ e LÍVIA MENDES CASTRO(4)
}

\begin{abstract}
RESUMO
A produção de flores constitui-se em enorme potencial ao Agribusiness brasileiro. No entanto, para se ter acesso ao competitivo mercado de flores, é necessário vencer algumas barreiras. Uma das encontradas para a expansão de algumas espécies ornamentais, a exemplo de Zantedeschia spp., é a inexistência de protocolos eficientes de micropropagação visando à produção de mudas sadias em escala comercial e a um preço competitivo. O objetivo deste trabalho foi desenvolver protocolo específico para micropropagação da cultivar Neroli tendo em vista a otimização do processo produtivo para ganho de escala e qualidade fitossanitária das mudas obtidas. Para tanto, utilizaram-se os seguintes sistemas de esterilização de meios de cultura: a) sistema tradicional com o uso de autoclave e frascos de vidro como recipientes e b) sistema semiautomatizado no qual o meio de cultura é esterilizado em máquina especial (esterilizador de meio de cultura) e distribuído em dois diferentes potes de plástico esterilizados por plasma: 1) com filtro inserido na tampa e 2) sem filtro inserido na tampa. Compararam-se protocolos de esterilização dos explantes, método de isolamento dos explantes meristemáticos, composição nutricional e composição de fitorreguladores dos meios de cultura. O desenvolvimento do sistema semiautomatizado proposto combinado com $4,44 \mu \mathrm{M}$ de benzilaminopurina (BAP) e uso de potes plásticos com filtro inserido nas tampas aumentaram a eficiência da micropropagação mensurada pelo comprimento médio das plântulas $(5,75 \pm 0,22)$, pelo número médio de brotos obtidos por explantes $(2,56 \pm 0,25)$ e pelo número médio de raízes $(7,22 \pm 0,31)$. O protocolo obtido pode auxiliar na redução dos custos desta ornamental, viabilizando-a comercialmente.
\end{abstract}

Palavras-chaves: copo-de-leite colorido, tipo de tampa, esterilização, benzilaminopurina.

\begin{abstract}
Micropropagation of Zantedeschia spp.: optimization of productive process

The production of flowers is a great potential to the Brazilian Agribusiness. However, to have access to the competitive market of flowers it is necessary to win some barriers. One of these barriers is the inexistence of efficient protocols for micropropagation of healthy seedlings by low cost. The aim of this work was the optimization of the productive process for scale up micropropagation of cultivar Neroli. Thus, were used the following systems of culture media sterilization: 1) traditional system using autoclave and glasses pots and 2) semi-automated system in which the culture medium is sterilized in the special machine and after distributed in two different plastic pots already sterilized by plasma process: pot with filter inserted on the caps and pot without filter insert on the caps. Explants sterilization protocols, technology for meristem tips isolation, nutricional composition of culture medium, phytoregulators concentration were tested. The development of semi-automated system proposed under optimal benzylaminopurine concentration (BAP- $1 \mathrm{mg} / \mathrm{L}$ ) and the use of plastic pots with filter insert on the caps increased the efficiency of the micropropagation process measured by the average length of the seedlings $(5.75 \pm 0.22)$, the average number of shoots obtained by explants $(2.56 \pm 0.25)$ and average number of roots $(7.22 \pm 0.31)$. The protocol obtained can help in reducing the cost of this ornamental, making it possible commercially. Key words: calla lily, cap type, sterilization, benzilaminopurine
\end{abstract}

\footnotetext{
(1) Recebido para publicação em 30/08/2007 e aprovado em 21/08/2008.

(2) Pesquisadora Científica, Instituto Agronômico (IAC), Av. Theodureto de Almeida Camargo, 1500, 13077-630 Campinas (SP). dargollo@iac.sp.gov.br

(3) Laboratório ProClone Biotecnologia e Produção de Mudas Matrizes de Laboratório LTDA, Rua dos Girassóis, 70, Caixa Postal 157, 13825-970 Holambra (SP), (19) 3802-1787. proclone@proclone.com.br

(4) Estagiária do IAC. liviamdecastro@yahoo.com.br
} 


\section{INTRODUÇÃO}

Zantedeschia sp. é uma ornamental herbácea conhecida como calla ou copo-de-leite colorido e internacionalmente como "calla lily", sendo no Brasil conhecida como copo-de-leite. Segundo o sistema de classificação de CRONQUIST (1981), o copo-de-leite pertence à família Araceae, gênero Zantedeschia. O gênero Zantedeschia é originário da África do Sul e é dividido em duas secções distintas (LETTY, 1973, SINGH et al., 1996). A seção I de Zantedeschia contém apenas uma espécie $Z$. aethiopica (copo-de-leite branco) a qual apresenta rizoma como órgão de armazenamento e não requer período de dormência. Segundo SNIJDER e VAN TUYL (2004), a secção Aestivae ou copo-de-leite colorido (secção II) compreende espécies com tubérculos como órgãos de armazenamento e requerem período de dormência no inverno (Z. rehmannii Engl., Z. jucunda Letty, Z. elliotiana (Watson) Engl., Z.pentlandii (Watson) Whittm., $Z$. albomaculata (Hook) Baill. and Z. valida (Letty) Y. Singh (SINGH et al., 1996).

$\mathrm{O}$ gênero Zantedeschia foi primeiramente descrito na literatura em 1687. Chegou à Nova Zelândia por volta de 1900 pela importação de sementes. Nove anos mais tarde, tinham-se os primeiros híbridos. Desde então, espécies de Zantedeschia têm sido melhoradas para a obtenção de híbridos e para o desenvolvimento de novas cultivares na Nova Zelândia. Inicialmente, a maioria das flores de calla lily produzidas era amarela (Zantedeschia elliottiana), mas hibridações com outras espécies, tal como Zantedeschia rehmannii, proporcionaram o desenvolvimento de outras cultivares com um largo espectro de cores. Em 1930, vários produtores aliados a pesquisadores da Nova Zelândia iniciaram experimentos de melhoramento genético, o que resultou na diversificação de cores e tamanhos dessas plantas (SEM AUTOR DEFINIDO, Disponível em: www.callas.net.nz).

Atualmente, a maioria das espécies de Zantedeschia tem sido melhorada geneticamente tendo-se por base espécies da secção II, as quais possuem uma maior variação de cores. Entretanto, essas cultivares são altamente susceptíveis à podridão causada pela bactéria Erwinia carotovora, séria doença do gênero Zantedeschia e principal doença da secção Aestivae, de ocorrência mundial (CORR, 1993; KUEHNY, 2000; WRIGHT e BURGE, 2000, REN et al. 2001). Esta bactéria anaeróbica facultativa causa amolecimento e podridão dos tecidos parenquimatosos de todos os órgãos da planta, resultando em perda da planta inteira (P'EROMBELON e KELMAN, 1980; WRIGHT, 1998). YAO et al. (1995) encontraram indícios de variação da resistência à bactéria Erwinia carotovora dentro da secção Aestivae de Zantedeschia. Apesar de pouca resistência encontrada nas cultivares de Aestivae, algumas como Neroli, Hazel Marie e Coral Sunset apresentaram-se menos susceptíveis à bactéria Erwinia carotovora e foram consideradas tão tolerantes quanto a um acesso de $Z$. rehmanii (SNIJDER, 2004; SNIJDER e VAN TUYL, 2002). Esta grave doença bacteriana é de difícil controle, sendo a prevenção a melhor maneira de se contornar o problema. A prevenção é feita pelo uso de material genético resistente ou pela aquisição de mudas sadias e indexadas pela cultura de meristemas.
Para o setor da floricultura, a micropropagação ou propagação clonal in vitro é uma biotecnologia amplamente empregada para um grande número de espécies (TOMBOLATO E COSTA, 1998). Esse processo, principalmente quando iniciado a partir de cultura de ápices meristemáticos, proporciona limpeza clonal com eliminação de diversos patógenos, resultando em mudas de boa qualidade fitossanitária (CROCOMO, 1986; FERREIRA et al., 1998), além da uniformidade e manutenção da identidade genética dos híbridos de alto valor comercial clonados (GROUT, 1990). No entanto, o alto custo do atual processo de micropropagação que vem sendo utilizado prejudica a eficiência do processo de produção de mudas de qualidade em escala comercial, impossibilitando, assim, a atuação das biofábricas brasileiras em mercados maiores, incluindo o mercado de exportação. O alto custo deve-se, em especial, à produção por sistemas de esterilizações em autoclave artesanais, as quais demandam grandes consumos de energia elétrica e tempo, e à falta de recipientes específicos (mais eficientes em trocas gasosas) em substituição aos frascos de vidro ora utilizados.

Visando à redução de custos de produção, as biofábricas brasileiras vêm buscando novas alternativas de equipamentos como, por exemplo, uma máquina de esterilização de meio de cultura com plasma para substituir o processo de esterilização por autoclave (Patente MU8103339-7, Monique Inês Segeren). Esta máquina, além do menor gasto com energia elétrica, apresenta a possibilidade pelo automatismo, da utilização de mão-deobra menos especializada, esterilizando na medida do consumo (sistema just in time) e não em grandes volumes pré-determinados. No entanto, há necessidade de pesquisas científicas com enfoque no desenvolvimento de diferentes tipos de potes para meios de cultura, em substituição aos frascos de vidro usados no sistema de esterilização por autoclave para proporcionar uma melhor adaptação ao novo sistema de esterilização com plasma. Além disso, há necessidade de se ajustar protocolo específico para as várias espécies e cultivares de Zantedeschia spp. de interesse comercial.

Nesse contexto, o presente trabalho teve como objetivo o desenvolvimento de protocolo específico para micropropagação da cultivar comercial Neroli, tolerante a bactéria $E$. carotovora, adaptado ao novo sistema de esterilização com plasma visando à otimização do processo produtivo para ganho de escala. Protocolos de esterilização dos explantes meristemáticos, método de isolamento desses explantes, composição nutricional e de fitorreguladores dos meios de cultura foram comparados a fim de demonstrar a eficiência de produção dentro do sistema de esterilização tradicional e utilização de frascos de vidro como recipientes e pelo novo sistema, no qual o meio de cultura é esterilizado na máquina e distribuído em dois tipos de potes plásticos já esterilizados por plasma: com filtro e sem filtro inserido na tampa.

\section{MATERIAL E MÉTODOS}

Brotos do tubérculo de uma única planta da cultivar Neroli selecionada nos campos experimentais da empresa Proclone Biotecnologia Ltda. foram coletados 
após o período de dormência. Após a desinfecção superficial dos brotos, procedeu-se à extração asséptica dos meristemas, os quais foram transferidos para o meio MS (MURASHIGE e SKOOG, 1962) acrescido de diferentes concentrações de fitorreguladores (item 2.2.).

Após o desenvolvimento dos meristemas em planta e a formação das brotações laterais, estas foram individualizadas e transferidas para diferentes meios de multiplicação "M" (descrito no item 2.3.). O meio de multiplicação foi preparado manualmente e esterilizado pelo sistema de esterilização por autoclave (quando se utilizou frascos de vidros); pelo processo de semiautomação, o meio foi preparado, esterilizado e distribuído pela máquina de esterilização (Patente MU8103339-7, Monique Inês Segeren) nos diferentes potes plásticos PET estéreis: redondos sem filtros inseridos nas tampas e retangulares com filtros inseridos nas tampas. Realizaramse repicagens mensais. Para efeito de controle de variáveis, os frascos (vidros e potes) foram mantidos sob mesmas condições ambientais: temperatura $\left(25^{\circ} \mathrm{C} \pm 2^{\circ} \mathrm{C}\right)$ e sob fotoperíodo de 16 horas sob luz branca incandescente (intensidade luminosa de 2000 lux $40 \mathrm{~W}$ marca Philips, à distância de $40 \mathrm{~cm}$ dos recipientes).

\subsection{Procedimentos de esterilização}

Para a desinfecção superficial desse material, dois procedimentos foram testados: 1) Imersão em solução de hipoclorito de sódio (preparada com $30 \mathrm{~mL}$ de produto comercial Cândida 5 a $6 \%$ em $200 \mathrm{~mL}$ de água destilada e esterilizada por 15 minutos); 2) Imersão inicial dos brotos em álcool etílico $70 \%$ por 10 segundos seguido de imersão em solução de hipoclorito de sódio (preparada com 25 $\mathrm{mL}$ de produto comercial 5 a 6\% (Cândida) em $200 \mathrm{~mL}$ de água destilada e esterilizada por 30 minutos), Ambos os procedimentos foram finalizados com 3 a 4 lavagens sucessivas em água esterilizada.

\subsection{Interação entre fitorreguladores e desenvolvimento de ápices mersitemáticos}

Após o isolamento dos ápices meristemáticos, transferiu-se o material para tubo de ensaio com meio MS com 3\% de sacarose, solidificado com 4,5 g/L de ágar e suplementado com as seguintes concentrações de fitorreguladores: 0,$00 ; 8,88 ; 17,76 \mu \mathrm{M}$ de BAP e 0,000 ; 0,057 e $0,570 \mu \mathrm{M}$ de AIA. Foram realizados nove tratamentos com cinco repetições por tratamento. Analisaram-se os seguintes parâmetros: oxidação do material, presença de calos basais, altura do eixo caulinar das plântulas, número de raízes.

\subsection{Efeito de diferentes doses de BAP na micropropagação do cultivar Neroli}

As plântulas com aspecto normal desenvolvidas no experimento anterior foram individualizadas e transferidas para frascos de vidro que continham meio "M" de multiplicação formado por meio MS com 3\% de sacarose, acrescido de 4,5 g/L de ágar e das seguintes concentrações de BAP $(0,0 ; 2,22 ; 4,44$ e $6,66 \mu \mathrm{M})$. Após 35 dias, avaliaram-se os seguintes parâmetros: número de brotos por propágulo, número de raízes, número de folhas.
2.4 Comparação do desenvolvimento e micropropagação de mudas da cultivar Neroli em diferentes potes plásticos com e sem filtro inserido na tampa

O meio "M", acrescido da dose de BAP que proporcionou melhor resultado quanto à taxa de multiplicação, foi distribuído em dois tipos de potes plásticos transparentes (PET): 1) retangular com filtro inserido na tampa; 2) redondo sem filtro inserido na tampa. $O$ filtro consiste em uma pequena abertura na tampa protegida por membrana Millipore, que impede a passagem de patógenos, mas permite uma maior troca gasosa (figura 1). Concomitantemente, para efeito de comparação, preparou-se manualmente o mesmo meio de cultura: a esterilização se deu pelo processo tradicional por autoclave e a distribuição do meio nos frascos de vidro, manual. Os propágulos foram colocados nesses diferentes potes e seu desenvolvimento, comparados pela análise dos seguintes parâmetros (após 35 dias de cultivo): número de brotos por propágulo, comprimento de plântulas e número de raízes.

O delineamento estatístico dos bioensaios foi inteiramente casualizado. A análise estatística foi realizada com a utilização do "software" SAS. Foram calculados os desvios-padrão das médias. Para a comparação de médias aplicou-se o teste de Tukey a $5 \%$ de probabilidade (GOMES, 1990).

\section{RESULTADOS E DISCUSSÃO}

A otimização das metodologias para os procedimentos de esterilização e isolamento dos ápices meristemáticos caulinares foi de extrema importância para o sucesso da obtenção de um banco de material homogêneo in vitro do genótipo comercial testado. Quanto aos procedimentos de esterilização, observou-se que a utilização de um pré-tratamento com álcool $70 \%$ por 10 segundos, somada a exposição ao agente germicida hipoclorito de sódio por um período maior de tempo (30 minutos), resultou em quase $96 \%$ de material sadio. $O$ procedimento de esterilização I, com ausência de prétratamento com álcool e menor tempo de exposição ao hipoclorito de sódio, resultou em apenas $40 \%$ de material não contaminado.

Os ápices meristemáticos caulinares inoculados em meio MS sem a adição de fitorreguladores foram os que apresentaram melhor desenvolvimento, tanto da parte aérea quanto de raízes, originando plantas com aspecto normal, as quais atingiram altura média do eixo caulinar de $1,4 \pm$ $0,47 \mathrm{~cm}$ em análise realizada aos 20 dias após a instalação do experimento e $3,2 \pm 0,35 \mathrm{~cm}$, aos 40 dias após instalação do experimento. Nos meios de cultura acrescidos de apenas AIA na concentração de $0,057 \mu \mathrm{M}$, também se obteve plantas de aspecto normal, porém menos desenvolvidas e com pequenos calos basais. Segundo AMMIRATO (1983), os calos basais são indesejáveis, pois, geralmente, provocam variabilidade genética, sobretudo na forma de poliploidização e aneuploidização. A fidelidade genética com a manutenção das características agronômicas de interesse é essencial para a micropropagação comercial de cultivares de alto valor comercial como Neroli, cultivar tolerante a bactéria $E$. carotovora. Todas as demais 
interações entre os fitorreguladores acarretaram alterações no desenvolvimento da planta, como formações de grandes calos basais e vitrificação das folhas.

Após a transferência, os ápices meristemáticos desenvolvidos em meio MS sem fitorreguladores foram então transferidos para frascos de vidro de $200 \mathrm{~mL}$ que continham meio de multiplicação "M" acrescido de diferentes doses de BAP $(0,0 ; 2,22 ; 4,44$ e $6,66 \mu \mathrm{M})$. A concentração que proporcionou melhor resultado na multiplicação das plântulas da cultivar Neroli foi $4,44 \mu \mathrm{M}$ de BAP, como pode ser observado na tabela 1 .

Os brotos obtidos foram, em seguida, transferidos para meio MS acrescido de 4,5 g/L de ágar e 4,44 $\mu \mathrm{M}$ de BAP e distribuídos nos diferentes potes plásticos com filtro e sem filtro inserido nas tampas. Como resultado, observase que, nos potes com filtro, o comprimento médio das plântulas foi de $5,75 \pm 0,22 \mathrm{~cm}$; o número médio de brotos obtidos foi de $2,56 \pm 0,25$ por explante e o número médio de raízes, de 7,22 $\pm 0,31$. Já nos potes sem filtro, o comprimento médio das plântulas obtidas foi $6,0 \pm 0,19$; o número médio de brotos por explante foi $1,8 \pm 0,23$ e o número médio de raízes por propágulo, 5,00 $\pm 0,45$. Plântulas desenvolvidas em frascos de vidro pelo sistema tradicional mostraram-se semelhantes às plântulas mantidas em potes sem filtro nas tampas: comprimento médio das plântulas de $6,2 \pm 0,36$; o número médio de brotos obtidos foi $1,9 \pm 0,27$ por explante e o número médio de raízes, $5,35 \pm 0,23$. Nota-se nas plântulas mantidas em potes com filtro taxa de multiplicação superior em relação às plantas colocadas nos potes sem filtro, tendo sido observado maior número de brotos e de raízes por explante (figura 2A). As plântulas mantidas nos potes sem filtro nas tampas apresentaram estiolamento e menor taxa de multiplicação, apresentando menor número de brotações, menor número de raízes e menor número de folhas (figura 2B). O maior comprimento das plântulas desenvolvidas nesse tipo de recipiente é explicado pelo seu estiolamento, verificado pelo maior comprimento do caule e menor número de nós, folhas e raízes.

Os potes adaptados com sistema de filtros inseridos nas tampas possivelmente permitiram uma maior troca de $\mathrm{CO}_{2}$ e etileno do interior dos potes com $\mathrm{O}_{2}$ do ambiente externo. Essa troca gasosa, sinalizada pela ausência de gotículas de umidade aderidas nas paredes dos potes com filtros inseridos nas tampas, hipoteticamente possibilitou às plantas melhor desenvolvimento, contribuindo, assim, para a produtividade da micropropagação. Resultados semelhantes foram obtidos por SOUZA et al. (1999). Os autores, estudando a influência dos fatores físicos na regeneração de brotos de repolho, observaram a ocorrência de estiolamento dos brotos, em virtude do acúmulo de compostos voláteis no interior dos frascos, quando se apertava a rosca das tampas nos frascos. MARINO et al. (1995) mediram o acúmulo de gases (CO2 e etileno) e registraram variação no acúmulo desses gases de acordo com as diferentes tampas plásticas e de alumínio utilizadas no experimento.

No sistema de micropropagação tradicional, o uso de recipientes fechados (sem filtros inseridos nas tampas) dificulta as trocas gasosas entre a atmosfera do recipiente de cultivo e o meio exterior e pode alterar o crescimento e o desenvolvimento das plântulas. Nessas condições, as plântulas podem não se desenvolver plenamente por limitações impostas pela composição da atmosfera dos frascos (BUDDENDORF-JOOSTEN e WOLTERING, 1994). Explica-se a redução do crescimento das plantas in vitro pela baixa capacidade fotossintética, em virtude da rápida queda da concentração do $\mathrm{CO}_{2}$ no recipiente (POSPISILOVÁ et al. 1992), pela baixa irradiância (LAKSO et al. 1986 citado por ERIG e SCHUCH, 2005), pelos altos níveis de açúcar do meio (GROUT, 1988), pela alta umidade relativa e pela ação do etileno, gerado e acumulado no interior dos frascos (BUDDENDORFJOOSTEN e WOLTERING, 1994). Segundo ERIG e SCHUCH(2005), as características específicas do cultivo in vitro podem tornar as plantas cultivadas nessas condições extremamente sensíveis quando forem transplantadas para a condição ex vitro, haja vista a condição ex vitro exigir das plantas uma significativa capacidade fotossintética. Esse fato pode explicar a grande taxa de mortalidade das plântulas na fase de aclimatização.

A utilização de tampas mais permeáveis (filtros permeáveis) aumentam a concentração de $\mathrm{CO}_{2}$ e, simultaneamente, reduzem a umidade relativa e a concentração de etileno ao redor da planta (KOZAI e KUBOTA, 2001). O acréscimo da concentração de $\mathrm{CO}_{2}$ promove o aumento da fotossíntese, em função de seu efeito direto sobre a enzima Rubisco (Ribulose 1,5 difosfato carboxilase) (BOWES, 1993; ARIGITA et al., 2002); propicia a regulação estomática; prepara as plantas para as condições autotróficas (ERIG e SCHUCH, 2005), e possibilita o encurtamento ou eliminação total de aclimatização ex vitro (KOZAI, 1991). O decréscimo na umidade relativa com a maior troca gasosa no frasco aumenta significativamente a taxa de transpiração da planta e, conseqüentemente, a absorção de água e de nutrientes (AITKEN-CHRISTIE et al. citado por ERIG e SCHUCH, 2005). Ao mesmo tempo, a redução da umidade relativa diminui a incidência de vitrificação nas plantas, favorece a formação de cutícula nas folhas e o funcionamento normal dos estômatos, aumentando a tolerância ao estresse hídrico (ZOBAYED et al., 2001) e facilitando a aclimatização das plantas. Com o aumento das trocas gasosas no recipiente de cultivo, a concentração de etileno também é reduzida.

O tecido apical de uma planta é local de intensa síntese de auxina. Este hormônio é transportado do ápice para o tecido imediatamente abaixo, onde promove alongamento celular (transporte polar de auxina) (CATO e CASTRO, 2006). Acontece que, não coincidentemente, a produção de etileno ocorre também no ápice (MARQUES, 1998). Segundo FERRI (1979), já em 1935, CROCKER, HITCHCOCK, WILCOXON e ZIMMERMAN descobriram que a auxina regulava a produção endógena de etileno e que muitos efeitos anteriormente atribuídos à auxina são na verdade efeitos do etileno (inibição do crescimento do caule e de raízes, epinastia, etc). Outra intrigante descoberta a respeito da ação do etileno em plantas refere-se à interação com outros hormônios ao nível de metabolismo, especialmente durante o desenvolvimento dos tecidos e na diferenciação celular (LIEBERMAN, 1979). Essa descoberta revela a exigência 
de níveis extremamente baixos de etileno para o desenvolvimento e crescimento das plantas, enquanto altos níveis são prejudiciais e podem ser inibitórios ou antagônicos. Como em cultura de tecidos há uma maior liberação de etileno promovido pelo estresse da planta e pelos ferimentos dos tecidos no momento do corte para as repicagens, é extremamente importante o sistema de filtro Millipore nas tampas dos potes, pois permite uma eficiente eliminação do excesso deste hormônio (na forma gasosa) para o meio externo, equilibrando e mantendo, assim, o nível ótimo - não somente de etileno, mas também de $\mathrm{O}_{2}$ e $\mathrm{CO}_{2}$ (importantes para diversas reações bioquímicas vitais para as plantas)

O acúmulo excessivo de etileno tem um efeito adverso no desenvolvimento das plantas, pois afeta a diferenciação, o desenvolvimento, a morfologia e o crescimento das plantas; diminui a expansão foliar, o comprimento dos brotos (JACKSON et al., 1991; ERIG e SCHUCH, 2005); inibe a regeneração de novos brotos (BIDDINGTON, 1992) e causa necrose apical nas plantas.

Conclui-se, portanto, que a utilização do sistema semi-automatizado proposto, combinado com a $\operatorname{BAP}(4,44$ $\mu \mathrm{M})$ e potes de plástico com filtros inseridos nas tampas, aumentou a eficiência da micropropagação da cultivar Neroli de Zantedeschia, contribuindo, dessa forma, para a diminuição dos custos envolvidos no processo produtivo de mudas em escala.

\section{CONCLUSÃO}

Conclui-se, portanto, que a utilização do sistema semi-automatizado proposto combinado com a adição de 4,44 $\mu \mathrm{M}$ de BAP ao meio MS e potes de plástico com filtros Millipore inseridos nas tampas possibilitaram um melhor desenvolvimento das plantas in vitro, observado pela maior taxa de multiplicação, maior número de brotos e de raízes por explante. As plântulas mantidas nos potes sem filtro nas tampas apresentaram estiolamento, menor taxa de multiplicação; menores números de brotos e de raízes por explante. $\mathrm{O}$ aumento da eficiência de micropropagação da cultivar Neroli de Zantedeschia descrito neste trabalho poderá contribuir para a diminuição dos custos envolvidos no processo produtivo de mudas em escala.

\section{AGRADECIMENTO}

Os autores agradecem à FAPESP pela concessão das bolsas de apoio técnico.

\section{REFERÊNCIAS}

AMMIRATO, P.V. Embryogenesis. In: EVAN, D.A., SHARP, W.R., AMMIRATO, P.V., YAMADA, Y, EDS. Handbook of Plant Cell Culture: Techniques for Propagation and Breeding, v I, Macmillan Publishing Company, New York, 82-123. 1983.

ARIGITA, L.; GONZÁLEZ, A.; TAMÉS, R.S. Influence of $\mathrm{CO}_{2}$ and sucrose on photosynthesis and transpiration of Actinidia deliciosa explants cultured in vitro.
Physiologia Plantarum, Copenhagen, v.115, p.166-173, 2002.

BIDDINGTON, N.L. The influence of ethylene in plant tissue culture. Plant Growth Regulation, The Hague, v.11, p.173-187, 1992.

BOWES, G. Facing the innevitable: plants and increasing atmospheric carbon dioxide. Annual Review of Plant Physiology and Plant Molecular Biology, Palo Alto, v.44, p.309-332, 1993.

BUDDENDORF-JOOSTEN, J.M.C.; WOLTERING, E.J. Components of the gaseous environment and their effects on plant growth and development in vitro. Plant Growth Regulation, Netherlands, v.15, p.1-16, 1994.

CATO, S.C., CASTRO, P.R.C. Redução da altura de plantas de sojacausada pelo ácido 2,3,5 triiodobenzóico. Ciência Rural, Santa Maria, v.36. n.3, p.981-984, 2006.

CORR, B.E. Zantedeschia research in the United States, past present and future. Acta Horticulturae Wageningen, v.337, p. 177-187, 1993

CROCOMO, O.J. Plant biotechnology in the agriculture and development in Brazil. In: SIMPÓSIO ANUAL DA ACADEMIA DE CIÊNCIAS DE SÃO PAULO, São Paulo, Brasil, Anais. v.11, p.53-71, 1986.

CRONQUIST, A. A integrated system of classification of flowering plants. New York: Columbia University Press, 1262p. 1981.

ERIG A.C.; SCHUCH M.W. Micropropagação fotoautotrófica e uso da luz natural. Ciência Rural, Santa Maria, v.35, n.4, p.961-965, jul-ago, 2005.

FERREIRA, M.E; CALDAS L.S; PEREIRAE.A. Aplicações da cultura de tecidos no melhoramento genético de plantas. In: TORRES, A.C.; CALDAS, L.S; BUSO, J.A. (ed). Cultura de tecidos e transformação genética de plantas. Brasília: Embrapa-SPI/Embrapa-CNPH. 864p, 1998.

FERRI, M.G. Fisiologia vegetal 2. São Paulo: Editora da Universidade de São Paulo, v.2, 392p. 1979

GOMES, F.P. Curso de estatística experimental. Piracicaba: Nobel, 1990. 468p.

GROUT, B.W.W. Meristem tip culture. In: POLLARD, J.W. \& WALKER, J.M. (ed) Methods in molecular biology: plant cell and tissue culture. New Jersey: Humana Press. 597p, 1990.

GROUT, B.W.W. Photosynthesis of regenerated plantlets in vitro and the stresses of transplanting. Acta Horticulturae, Wageningen, v.230, p.129-135, 1988.

JACKSON, M.B.; ABBOTT, A.J.; BELCHER, A.R.; HALL, K.C.; BUTLER, R.; CAMERON, J. Ventilation 
in plant tissue cultures and effects of poor aeration on ethylene and carbon dioxide accumulation, oxygen depletion and explant development. Annals of Botany, London, v.67, p.229-237, 1991.

KOZAI, T. Micropropagation under photoautotrophic conditions. In: DEBERGH, P.C.; ZIMMERMAN, R.H. (eds). Micropropagation-technology and aplication. Dordrecht: Kluwer Academic, p.447-469, 1991.

KOZAI, T; KUBOTA, C. Developing a photoautotrophic micropropagation system for woody plants. Journal of Plant Research, Tokyo, v.114, p.525-537, 2001.

KOZAI, T.; NGUYEN, Q.T. Photoautotrophic micropropagation of woody and tropical plants. In: JAIN, S.M.; ISHII, K. Micropropagation of woody trees and fruits. Dordrecht : Kluwer Academic. p.757-781, 2003.

KUEHNY, J.S. Calla history and culture. Hort.Technology, Alexandria, v.10, p.267-274, 2000.

LETTY, C. The genus Zantedeschia. Bothalia, Pretoria, v.11, n. 1 e 2, p.5-26, 1973

LIEBERMAN M. Biosynthesis and action of ethylene. Annual Reviews of Plant Physiology, Palo Alto v.30, p. 533-591, 1979.

MARINO, G.; BERARDI, G.; ANCHERANI, M. The effect of the type of closure on the gas compositionof the headspace and the growth of GF 677 peach x almond rootstack cell suspension culture. In Vitro Cellular Development Biology Plant, Columbia, v.31, n.4, p.207$210,1995$.

MARQUES, D.A, CROCOMO, O.J.; SHEPHERD, S.L. Influência de fitorreguladores sobre o desenvolvimento de gemas axilares de explantes caulinares de Chrysanthemum morifolium cultivado in vitro, Revista Brasileira de Botânica, São Paulo, v.21, n.2, p.141-147, 1998.

MURASHIGE, T.; SKOOG, F. A revised medium for rapid growth and bio assays with tabacco tissue cultures. Physiologia Plantarum, Copenhagen, v.15, p.473-497, 1962.

P'EROMBELON, M.C.M.; KELMAN M,A. Ecology of the soft rot Erwinia. Annual Review of Phytopathology, Palo Alto, v.18, p.361-387, 1980.

POSPISILOVÁ, J.; SOLAROVÁ; CATSKY, J. Photosynthetic responses to stress during in vitro cultivation. Photosynthetica, Dordrecht, v.26, p.3-18, 1992.

REN, J.; PETZOLDT, R.; DICKSON, M.H. Screening and identification of resistance to bacterial soft rot in Brassica napa. Euphytica, Dordrecht, v.118, p.271-280, 2001.
SEM AUTOR DEFINIDO. Getting to Know callas. A brief introduction to the botanical classification and morphology of the genus Zantedeschia . Disponível em: www.callas.net.nz. Acesso em 20/08/2005.

SINGH, Y.; VAN WYK, A.E.; BAIJNATH, H. Taxonomic n o t es on th o g n u s Zantedeschia Spreng. (Araceae) in southern Africa.South African. Journal of Botany. v.62, p.321-324, 1996.

SNIJDER, R.C.; VAN TUYL, J.M. Evaluation of tests to determine resistance of Zantedeschia spp. (Araceae) to soft rot caused by Erwinia carotovora sub sp. Carotovora. European Journal of Plant Pathology, Dordrecht, v.108, p.565-571, 2002

SNIJDER, R.C. Genetics of Erwinia resistance in Zantedeschia: impact of plastome-genome incompatibility. Netherlands, Wageningen Universiteit. Tese de Doutorado. 112p, 2004.

SNIJDER, R.C.; VAN TUYL, J.M. Breeding for resistance in Zantedeschia spp.. (Araceae) against soft rot caused by Erwinia carotovora subsp. carotovora. Acta Horticulturae, Wageningen, v.570, p. 263-266, 2004.

SOUZA, C.M.; PINTO, J.E.B.P.; RODRIGUES, B.M.; MORAIS, A.R.; ARRIGONI-BLANK, M.F. Influência dos fatores físicos na regeneração de brotos em repolho. Ciência e Agrotecnologia, Lavras, v. 23, n.4, p.830-835, 1999.

TOMBOLATO, A.F.C; COSTA, A. M. M. Micropropagação de plantas ornamentais. Campinas: Instituto Agronômico de Campinas. Boletim técnico, n. 174, p. 58-62, 1998.

WRIGHT, P. A soft rot of calla (Zantedeschia spp..) caused by Erwinia carotovora subsp. carotovora. New Zealand Journal of Crop and Horticultural Science, New Zealand, v.26, p.331-334, 1998.

WRIGHT, P.J.; BURGE, G.K. Irrigation, sawdust mulch, and Enhance $(\mathrm{R})$ biocide affects soft rot incidence, and flower and tuber production of calla. Journal of Crop and Horticultural Science, New Zealand, v.28, p.225$231,2000$.

YAO, J.K.; ROWLAND, R.E.; COHEN, D. Interspecific albino and variegad hybrids in the genus Zantedeschia. Plant Science, London, v.109, p.199-206, 1995.

ZOBAYED, S.M.A.; AFREEN, F.; KOZAI, T. Physiology of Eucalyptus plantlets grown photoautotrophically in a scaled-up vessel. In vitro Cellular and Developmental Biology Plant, New York, v.37, p.807-813, 2001. 
Tabela 1: Efeito de doses de benzilaminopurina (BAP) na multiplicação in vitro do cultivar Neroli de Zantedeschia, após 35 dias de cultivo: Brotos ( $\mathrm{N}^{\circ}$ brotos por propágulo); Raízes (Número de raízes por propágulo); Folhas (número de folhas por broto). Os dados representam a média de 20 plantas por tratamento

Table 1: Influence of benzilaminopurine (BAP) doses in the Zantedeschia cv. Neroli micropropagation 35 days after explants inoculation: Shoots/explant; Roots/explant; Leaves/explant. Data represent the average of 20 plants/tratament

\begin{tabular}{cccc}
\hline BAP( $\boldsymbol{\mu M})$ & $\begin{array}{c}\text { Brotos } \\
\text { shoots }\end{array}$ & $\begin{array}{c}\text { Raízes } \\
\text { roots }\end{array}$ & $\begin{array}{c}\text { Folhas } \\
\text { leaves }\end{array}$ \\
\hline 0,00 & $1,8 \mathrm{a}$ & $6,0 \mathrm{a}$ & $4,0 \mathrm{a}$ \\
2,22 & $2,1 \mathrm{~b}$ & $6,1 \mathrm{~b}$ & $5,0 \mathrm{~b}$ \\
4,44 & $2,3 \mathrm{c}$ & $6,2 \mathrm{~b}$ & $6,1 \mathrm{c}$ \\
6,66 & $2,4 \mathrm{c}$ & $5,9 \mathrm{c}$ & $5,9 \mathrm{~d}$ \\
$\mathbf{C V}$ & $15,2 \%$ & $15,2 \%$ & $15,2 \%$ \\
\hline
\end{tabular}

Médias seguidas por letras distintas diferem entre si pelo teste de Tukey, a 5\% de probabilidade. Desvios-padrão: brotos: 1,31; raízes: 1,91 e folhas: $0,81 . \mathrm{CV}=$ coeficiente de variação.

Averages denoted by same letter are not significantly different by Tukey's test at the $5 \%$ probability level. Standard deviation of mean: shoots: 1,31; roots: 1,91 and leaves: 0,81 . $C V=$ coefficient of variation.
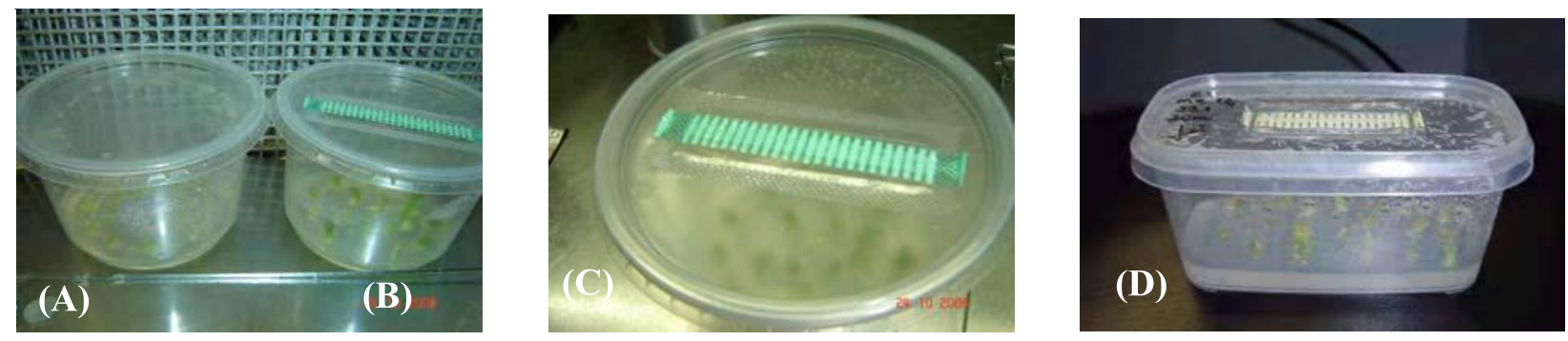

Figura 1: (A) Pote plástico transparente (PET) redondo sem filtro inserido na tampa, com mudas recém-inoculadas;

(B) Pote plástico transparente (PET) redondo com filtro inserido na tampa, com mudas recém-inoculadas; (C) Aspecto detalhado da tampa com filtro, protegido por membrana Millipore. (D) Pote plástico transparente (PET) retangular com filtro inserido na tampa, com mudas recém-inoculadas

Figure 1: (A) Seedlings just inoculated in round transparent plastic pot (PET) without filter insert on the caps; (B) Seedlings just inoculated in round transparent plastic pot (PET) with filter insert on the caps; (C) Detailed aspect of cap with filter protected by Millipore membrane; (D) Seedlings just inoculated in rectangular transparent plastic pot (PET) with filter insert on the caps. 

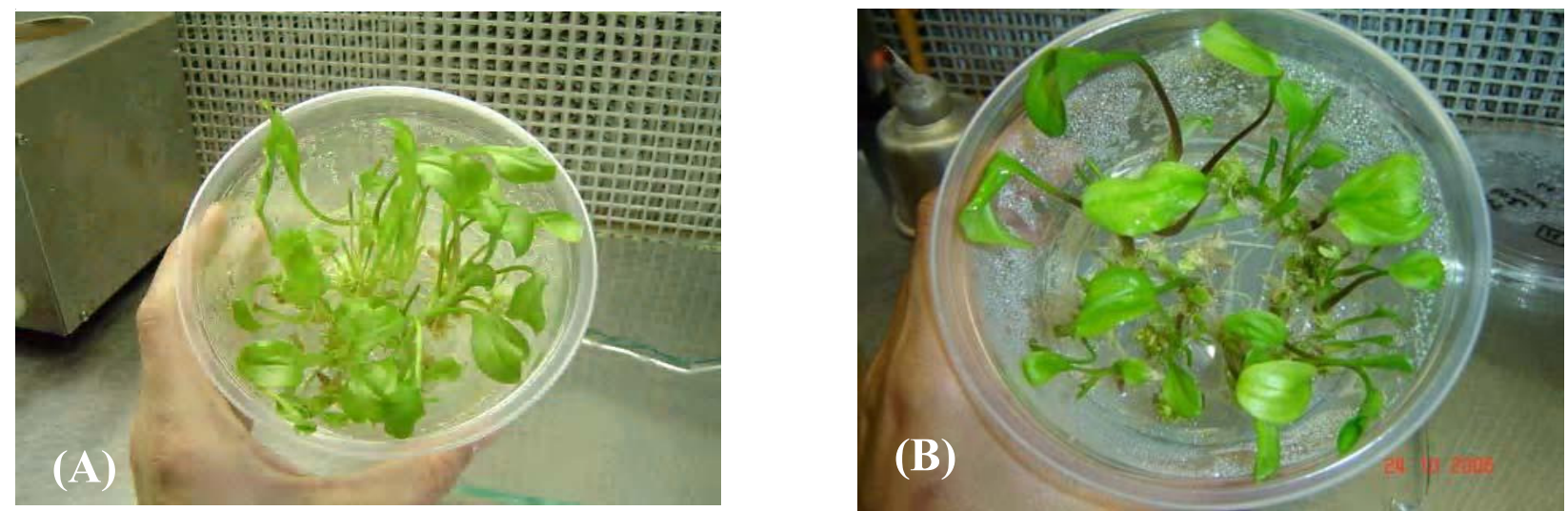

Figura 2: Zantedeschia spp. (cultivar Neroli) micropropagado em diferentes recipientes contendo meio de cultura MS acrescido de BAP $(4,44 \mu \mathrm{m})$. (A) Pote plástico transparente redondo com filtro inserido na tampa após 35 dias de cultivo mostrando excelente fator de multiplicação; (B) Pote plástico transparente redondo, sem filtro inserido na tampa após 35 dias de cultivo mostrando estiolamento e menor taxa de multiplicação.

Figure 2: Zantedeschia spp. (Neroli cultivar) micropropagated in different plastics pots with MS medium increased of $B A P(4,44 \mu \mathrm{m})$. (A) Use of transparent plastic pot with filter insert on the caps after 35 days of the cultivation showing excellent multiplication factor; (B) Use of transparent plastic pots without filter inserto $n$ the caps after 35 days of cultivation showing etiolared and smallest rate of multiplication. 